\title{
La Fonda Filosófica: Revisão de ComCiência
}

\author{
Robert Martins Junqueira ${ }^{1}$ \\ ${ }^{1}$ Affiliation not available
}

June 7, 2021

Redigimos este texto para a disciplina de Cultura Científica e Comunicação de Ciência da Pós-Graduação em Gestão e Políticas de Ciências e Tecnologia da Faculdade de Ciências Sociais e Humanas da Universidade Nova de Lisboa, ministrada por Ana Sanchez e António Granado.

Na secção "Nosotros" da página Web de La Fonda Filosófica (https://www.lafondafilosofica.com/ nosotros/), Darin McNabb veste a camisola de lente e afiança ter sido criado este projeto, em 2011, com vista acima de tudo a äpoiar a formação (apoyar la formación)" daquela/es que têm sido sua/eus estudantes no seio das disciplinas que ministra na Licenciatura em Filosofia do Instituto de Filosofía da Universidad Veracruzana em Xalapa (Vera Cruz, México), nomeadamente Estética e Filosofia Política. Pode ser dito, por tanto, que estamos diante de um reforço pedagógico. Ou então - se tivermos em conta que tudo indica que o alcance de La Fonda Filosófica (doravante LaFF) ultrapassa bastante o núcleo dos estudantes de McNabb, a começar por nós, que nunca tomamos assento numa sala de aulas xalapeña-, mais acertadamente diremos estar em face de algo mais geral do que um reforço pedagógico, que inclui mas ultrapassa este: estamos, acima de tudo, sob o teto de um esforço de comunicação. O objetivo do presente trabalho é dar a conhecer o melhor possível - dentro dos limites de extensão que nos foram impostos e das nossas eivas intelectuais - o que é $L a F F$ sob o prisma da comunicação. Para tal, procuraremos descobrir, em primeiro lugar, qual é o propósito por detrás desta iniciativa; em seguida, identificaremos a/os destinatária/os deste esforço de comunicação; então, abordaremos as questões sobre a consistência de $L a F F$ e sobre os meios por meio dos quais a mesma é desenvolvida; finalmente, serão colocados alguns dados na balança para comentar o impacto de $L a F F$ sem cair em ledo engano.

\section{1: Propósito}

$L a F F$ é um esforço de comunicação. Tem, por isso, que ter um propósito? Não somos suficientemente aventureiros para meter as mãos no fogo, seja a favor do 'sim' ou do 'não'. Podemos, contudo, facilitar a vida a quem vier a debruçar-se sobre as peças de um quebra-cabeças de tal forma duro de montar e afiançar que, se por acaso existem esforços de comunicação carentes de qualquer finalidade, esses casos não devem insuflar qualquer fôlego de lei, pois outros há que de propósito não carecem, como seja o de fazer-se ao jogo de paciência que é responder a tal pergunta, ou então o que nos trouxe até aqui, que é o esforço que representa $L a F F$. Esta página Web tem, de facto, um intuito. Caso contrário, não poderia ler-se em "Nosotros" que tudo passa por um esforço no sentido de clarificar o que de complicado existe nas ideias filosóficas, elucidando-as tão lapidar e instrutivamente quanto seja praticável. Contudo, o propósito de $L a F F$ não se fica por aqui: é também sob o desígnio de estimular a leitura de grandes títulos da história da Filosofia que esta iniciativa se tem vindo a desenrolar, sendo um pressuposto que os conteúdos produzidos não são mais do que aperitivos numa ementa que recomenda que se vá comer o resto da refeição nas páginas da tradição. Tendo em conta o que foi dito até agora, talvez não constitua um atentado ao bom senso procurar sintetizar o propósito de $L a F F$ com recurso a uma tradução do próprio título do empreendimento para A Cantina Filosófica, ao invés de Pousada, Albergue ou Pensão: o propósito de LaFF é dar a comer entradas filosóficas. É verdade 
que é uma cantina na qual apenas são servidos os primeiros pratos, mas não só não poderão queixar-se a/os comensais de publicidade enganosa como também abandonarão a mesa simultaneamente saciados e com água na boca.

\section{2: Destinatária/os}

A quem é que $L a F F$ pretende dar de comer? Na linha da frente estão, como já deve estar claro (ver acima), estudantes de McNabb. Este verdadeiro chef philosophique, que concluiu o Doutoramento no Boston College em 1997 e ensina na Universidad Veracruzana desde 1998, já terá alimentado e estimulado o apetite de imensa/os estudantes. Basta ver que $L a F F$ existe desde meados de 2011, pelo que em meados de 2021são contas fáceis de fazer-McNabb já leva 10 anos a servir travessas de antepasto em matéria de filosofia para fazer as delícias daquela/es que frequentam as disciplinas por ele ministradas (v. supra). Assim, os factos sugerem que a resposta à pergunta sobre a/os destinatária/os de LaFF é muito sencilla: o esforço de comunicação de ciência - muito particularmente de história da filosofia - que há pouco designamos de 'Cantina Filosófica' (supra) tem como destinatária/os a/os estudantes de McNabb, este que desempenha o papel de enunciador nas comunicações que se dão no espaço virtual de $L a F F$. Sem precipitações, convém não fechar o assunto por aqui; pois, mesmo que fosse legítimo limitar a/os destinatária/os de um esforço de comunicação ao público-alvo - isto se considerássemos que todo o esforço deste tipo implica um propósito e que daí resulta sempre a identificação de um auditoire visé-, o âmbito da comunicação em geral não deixaria de ser muito mais vasto. Em comunicação, é tida em conta qualquer relação que seja estabelecida entre quem enuncia e quem interpreta; independentemente de haver um fito no sentido de chegar a determinada/o intérprete ou de não haver, importa é que seja estabelecido o elo comunicativo, observável sempre que seja possível identificar uma sede de enunciação e outra de interpretação (para saber mais sobre este assunto leia-se Lane 2014, 66-69). Como podemos ver pelo nosso próprio exemplo e também veremos mais adiante (v. 'Balanço') num âmbito mais alargado, esta iniciativa não só está aberta a chegar como de facto é evidente que chega a um número de intérpretes que ultrapassa as turmas de McNabb. Se de facto se declara (v. supra) que a/os destinatária/os de $L a F F$ são estudantes de uma das pessoas responsáveis pela tradução da Obra filosófica reunida de Charles S. Peirce para castelhano, há ainda assim que lançar uma questão à qual só McNabb será capaz de responder: não constitui, a significativa fatia do grande público internacional capaz de aceder tanto à internet quanto à língua castelhana, o público-alvo de $L a F F$ ?

\section{3: Consistência}

Muito temos já falado sobre $L a F F$, mas pouco se falou sobre a sua consistência. Em que consiste, afinal, esta iniciativa? Acima de tudo, a Fonda é um repositório de vídeos, faixas de som e transcrições de sessões dedicadas a protagonistas e temáticas caras no campo da história da filosofia, como sejam Platão, Aristóteles, Gottfried Wilhelm Leibniz, Jean-Jacques Rousseau, Charles S. Peirce, John Dewey, Martin Heidegger, JeanPaul Sartre e Noam Chomsky, por um lado; e, por outro, a ética, a estética, a ideologia, o pragmatismo, a semiótica e a teoria política. Tudo isto e muito mais a partir dos programas das disciplinas ministradas por McNabb, mas não só, uma vez que este declara, em "Nosotros" (v. supra) que vai "fazendo vídeos sobre outros temas do seu interesse e competência (haciendo vídeos sobre otros temas de mi interés y competencia)". Os vídeos estão dispostos na página de forma ordeira, bem categorizados num índice que se apresenta à esquerda, mas a página incorpora, ainda assim, um motor de busca interno. A cada prato - recorremos a esta expressão porque não só de vídeos se trata, como dissemos antes (supra) —é atribuída uma página própria, na qual se pode encontrar o ficheiro áudio e a transcrição, a que no universo de $L a F F$ se designa de "guião (guión)", disponíveis para download em MP3 e PDF, respectivamente. LaFF funciona, também, como plataforma de comunicação sobre si mesma, uma vez que qualquer pessoa interessada pode tornar-se subscritor/a; o que, segundo se lê na página, tem interesse por duas razões: a primeira, é que McNabb ficará sinceramente agradecido; a segunda é que quem subscreve receberá uma notificação via email sempre que a equipa de $L a F F$ acrescentar mais um título à ementa. 


\section{4: Meios}

Os meios são tudo aquilo que se encontra numa posição intermédia; quero dizer, tudo aquilo que, sem se confundir com a página Web de $L a F F$, faz parte direta ou indiretamente da mesma, constituindo-a ou veiculando-a. É verdade que uma revisão exaustiva dos meios levar-nos-ia a uma regressão ao princípio dos tempos - que é para não dizer 'ao infinito'-, o que originaria uma desorientação tal que, no meio dela, poderia ocorrer que fosse fomentado o levantamento de questões tão complexas como a de saber se o próprio Big Bang, as teorias da Relatividade Restrita e da Relatividade Geral ou a Batalha de Tannemberg com que se encerrava o Verão de 1914 na Prússia Oriental - travada onde é atualmente a cidade de Olsztyn, na Polônia - devem ser ou não metidos ao barulho no que toca a entender de que meios se vale LaFF para trazer à luz do ecrã as suas maravilhosas iguarias filosóficas. Por conta das limitações inerentes à condição finita de quem engrossa as fileiras da humanidade, não nos será possível ir tão longe. Desengane-se, contudo, quem pensa que choraremos a nossa miséria, pois apesar de termos o dom das lágrimas, é de bom grado e com modéstia que abraçamos a nossa fragilidade, tal como a desta nossa sintética exposição. A nossa ambição não é senão esta: descobrir i) quem compõe a equipa de $L a F F$, ii) se há e de onde vem o financiamento para dar corda à Fonda, e iii) quais são os instrumentos que formam a parafernália técnica que permite a confeção e a disseminação do pasto filosófico destinado, antes de tudo, a estudantes de McNabb.

\section{1: Equipa}

Por muito difícil que seja acreditar que os 230 vídeos - número confirmado no dia 20 de maio de 2021 - com os respetivos guiões, tenham sido planeados, redigidos, ensaiados e interpretados - no sentido artístico da representação de um papel—, gravados, editados, carregados e disseminados por uma só pessoa, é assim que as coisas parecem ter-se sucedido. Tudo aponta para aí, quero dizer, $L a F F$ é uma monumental iniciativa de uma pessoa só: Darin McNabb. Assim, os dedos de uma mão chegam e sobram para contar quantos membros constituem a equipa de $L a F F$. De modo a tornar este número mais interessante para o ouvido, sugerimos que se apure outra forma de dizer 'um', como seja por via da afirmação de que a equipa por detrás desta iniciativa filosófica é constituída por um número ímpar inferior a dois. Tudo se passa, enfim, entre McNabb e quem assume a posição de intérprete; pelo que, no limite, poderá ser dito que a equipa de $L a F F$ é constituída pelo investigador especializado no pensamento de Peirce e por quem se senta para comer na mesa que McNabb põe, ou pelo menos pela tropa de barro que subscreve e vai deixando comentários que aquele tem certamente em consideração, pois raro será encontrar um comentário que o mesmo tenha deixado sem resposta.

\section{2: Financiamento}

Tudo leva a crer que há financiamento por trás de $L a F F$, pois: um domínio próprio na internet não se paga sozinho; o tempo de trabalho de um perito do calibre de McNabb não deve custar pouco; os materiais para gravação e o software para a edição de vídeo não são, normalmente, baratos; e a gestão da página Web, das plataformas e das redes sociais também não se fazem sem investimento. Por isso, cabe inquirir: de onde vem o dinheiro? Uma vez que não há, em nenhuma das páginas de $L a F F$, referência a qualquer fonte de financiamento, tomamos a liberdade de lançar duas hipóteses, que nos parecem ser as mais viáveis: ou $i$ ) a Fonda é financiada secretamente por algum tipo de mecenatismo discreto, ou ii) todo o trabalho destes últimos dez anos saiu diretamente do couro de McNabb. Se fossemos obrigados a ler nas estrelas, diríamos tratar-se $L a F F$ de um caso exemplar em que um professor investe não pouco do seu tempo e seguramente um conjunto significativo de recursos materiais para dar mais de si - e, neste particular, mais da filosofia - para toda/o aquela/e que se dispuser a aprender com gosto.

\section{3: Instrumentos Conexos}

Como disse Ana Sanchez, numa mensagem eletrónica que nos foi reencaminhado por uma colega a pedido da anterior (Pinto 2021), "numa iniciativa de comunicação, o canal de comunicação é a própria iniciativa (por exemplo, um evento). Claro que pode haver outros canais para dar a conhecer a iniciativa (por exemplo, 
anúncios de um evento) e esses podem ser também mencionados pois são a estratégia para chegar ao públicoalvo (e conseguir que participem no evento)". Nesta iniciativa de comunicação, o canal é o próprio sítio Web de LaFF. Contudo, em conformidade com o que disse Sanchez, outros canais há que servem de instrumentos para disseminar esta iniciativa, permitindo a McNabb chegar ao público da Fonda, como sejam Youtube, Spotify, Vimeo, Facebook e Google Drive. Os instrumentos agora listados servem um fito de divulgação; mas não só, pois alguns deles integram mesmo a página Web, permitindo que esta ofereça tudo aquilo a que quem se senta à mesa de McNabb tem direito: vídeos, ficheiros de som e os guiões. Estes últimos estão no corpo da página, em texto, mas é só através de um link Google Drive que podem ser descarregados em MP3, o mesmo sendo verdade com respeito aos textos, neste caso passíveis de serem descarregados em PDF. O Youtube também excede, no seio da Fonda, a função de ajudar a chegar ao público-alvo, pois é graças à possibilidade de incorporar vídeos da plataforma de vídeos da Google na Linguagem de Marcação de Hipertexto - o bloco de construção mais básico da Web que normalmente é referido pelo acrónimo HTML - que é possível degustar todos os petiscos filosóficos de McNabb diretamente na página Web de LaFF. Para além dos instrumentos agora referidos, certo é que McNabb não poderia levar esta sua iniciativa a bom porto sem dispor de material de gravação e de edição, tal como de muitos e bons livros.

\section{5: Balanço}

Seria bom ter acesso às estatísticas da página Web da Fonda, pois tal permitir-nos-ia fazer um balanço mais detalhado dos resultados de 10 anos de atividade desta iniciativa de McNabb. Tal, infelizmente, não está ao nosso alcance, pelo que nos sentimos desarmados. Contudo, tendo em conta que os vídeos incorporados na página Web estão alojados do Youtube, talvez seja através das métricas públicas desta plataforma a melhor forma de obtermos dados suficientes para tecer algumas considerações avisadas sobre o impacto desta iniciativa. Para começar, vejamos quantas visualizações têm os 230 vídeos de $L a F F$. Todos estes dados (supra et infra) são do dia 20 de maio de 2021. A unidade de referência será o milhar, pois nenhum vídeo tem menos de mil visualizações, e nenhum ultrapassa o milhão. Aliás, o vídeo com menos visualizações tem cerca de 4 mil e aquele que mais vezes foi visualizado soma cerca de 981 mil. Dando notícia de que todos os arredondamentos foram feitos ao milhar, resta-nos dizer que a soma das visualizações de $L a F F$ no Youtube é a que se segue: $149+27+30+193+86+63+43+76+207+32+91+83+42+55+105+$ $62+221+51+128+115+91+43+40+217+204+99+11+59+33+76+39+30+25+$ $24+177+93+84+290+121+62+47+73+145+65+56+48+41+38+20+39+33+$ $47+60+30+28+20+155+95+63+147+93+65+52+416+199+49+163+56+102$ $+60+144+127+41+147+74+55+110+51+39+33+29+189+981+185+519+154$ $+82+75+64+55+37+27+24+19+216+47+50+25+19+253+119+92+77+61+$ $52+166+91+71+120+59+64+48+53+39+47+35+38+36+33+29+29+111+$ $100+369+38+19+14+11+9+28+9+7+21+6+6+23+6+5+5+5+20+22+4$ $+4+20+4+4+6+25+21+22+19+104+22+35+216+91+98+14+35+65+23+$ $41+194+27+100+73+67+13+49+36+33+34+45+27+77+23+38+22+30+22$ $+25+93+18+56+22+14+13+37+13+15+30+44+10+28+17+23+12+22+14$ $+17+14+12+37+92+132+76+45+107+59+31+65+21+46+19+57+14+56+$ $15+60+13+93+42+27+14+39+55+84+31+27$, o que dá um total de 15935 milhares (cf. https://www . youtube. com/channel/UC6GbAKHWYUJDWlkxY6HPldg). Ora, assim sendo, só no Youtube $L a F F$ soma cerca de 15.935.000 visualizações. Quanto ao número de subscrições, uma vez que o número destas na página Web também só McNabb sabe, voltaremos a atentar ao Youtube, onde são já 209 mil. Ora, atendendo a estes números - e por muito que McNabb continue a afirmar serem estudiantes de La Ciudad de las Flores o público-alvo da Fonda - qualquer análise de comunicação de ciência que procure fazer um balanço do sucesso desta iniciativa deverá, ao considerar o impacto, ter em conta que o alcance da mesma excede em muito o seu público-alvo. Estamos seguros que é impossível terem sido apenas estudantes de McNabb a saborear a cultura gastronómica de $L a F F$. Caso contrário, cabe perguntar quase como quem exclama: madre mía, ¿cuántas personas integran las clases de McNabb en la Universidad Veracruzana? É sempre possível alegar que um pequeno grupo de pessoas é responsável pelos quase 16 milhões de visualizações que somam os vídeos 
de LaFF; mas, que fique ónus da prova para quem tal afirmar. Quanto a nós, resta dizê-lo taxativamente: o balanço só pode ser positivo, quero dizer, $L a F F$ é uma iniciativa de comunicação de ciência que continuará a marcar época, pois conjuga o seu carácter in fieri e a possibilidade de evolução que daí advém com um sucesso inconcusso e digno de admiração. Tudo o que foi dito até agora, de todo o modo, foi só um cheirinho do que é $L a F F$. Sabemos, porém, que para 'bom prato' querer saborear uma das iguarias de McNabb, basta o perfume. Por lo tanto, deixo a arrefecer nesta janela a ligação para uma apetitosa discussão da natureza da famanaz 'máxima pragmática' de Peirce (https://www. lafondafilosofica.com/la-maxima-pragmatica), o segundo dos 230 pratos a serem acrescetados à ementa da Fonda nestes dez anos de serviço público de McNabb. Vamos comer? Então, como suele decir o nosso chef, buen provecho!

\section{6: Referências}

Lane, Robert. «Peircean Semiotic Indeterminacy and Its Relevance for Biosemiotics». Em Peirce and Biosemiotics: A Guess at the Riddle of Life, editado por Vinicius Romanini e Eliseo Fernández, 51-78. Biosemiotics, 1875-4651 11. Dordrecht: Springer, 2014. https://doi.org/10.1007/978-94-007-7732-3_4

Pinto, Ligia. Carta para Alexandre Rocha, Ana Aranda, David Farto, Fernando Borges, Joana Cruz, Lídia Nóbrega, Nádia Marques, Ricardo Cordeiro, Robert Junqueira, Ana Sanchez e António Granado. «FW: PGCT - Análise evento comunicação de ciência», de 27 de abril de 2021 às 10:02. 